\title{
BMJ Open Changes in preventive care utilisation and its influencing factors among Chinese adults before and after the healthcare reform: cross-sectional evidence from the China Health and Nutrition Survey in 2004-2015
}

\author{
Ting Ting Wu (D) , , ,2,3 Wei Wei Liu, ${ }^{1,2,3}$ Mao Zou, ${ }^{1,2,3}$ Xun Lei, ${ }^{1,2,3}$ Qiang Yang, ${ }^{4}$
} Manoj Sharma, ${ }^{5}$ Yong Zhao (D) , ${ }^{1,2,3}$ Zu Min Shi ${ }^{6}$

To cite: Wu TT, Liu WW, Zou $\mathrm{M}$, et al. Changes in preventive care utilisation and its influencing factors among Chinese adults before and after the healthcare reform: cross-sectional evidence from the China Health and Nutrition Survey in 2004-2015. BMJ Open 2020;10:e038763. doi:10.1136/ bmjopen-2020-038763

- Prepublication history for this paper is available online. To view these files, please visit the journal online (http://dx.doi org/10.1136/bmjopen-2020038763).

Received 15 April 2020 Revised 05 July 2020 Accepted 18 August 2020
Check for updates

(C) Author(s) (or their employer(s)) 2020. Re-use permitted under CC BY-NC. No commercial re-use. See rights and permissions. Published by BMJ.

For numbered affiliations see end of article.

Correspondence to

Dr Yong Zhao;

zhaoyong@cqmu.edu.cn

\section{ABSTRACT}

Objective China launched its health reform in 2009.

This study aimed to assess changes in preventive care utilisation (PCU) and its relationship with the healthcare reform.

Design A cross-sectional study using demographic characteristics, socioeconomic status, environmental factors, and lifestyle and health status data of adults from five waves (2004-2015) of the China Health and Nutrition Survey (CHNS) was conducted. Multilevel mixed-effects logistic regression models were used.

Setting Data were derived from urban and rural communities of nine provinces in China.

Participants Data were obtained from five waves of the CHNS, with 9960 participants in 2004, 9888 in 2006, 10286 in 2009, 9709 in 2011, and 10628 in 2015. Outcome The primary outcome was PCU.

Results PCU in 2004-2015 among adults was 3.29\%, $3.13 \%, 3.77 \%, 4.95 \%$ and $2.73 \%$, respectively. Whether before or after the health reform, having a history of disease and female gender were positive influencing factors of PCU. Before 2009, PCU was significantly associated with gender, income, medical insurance status and region. Age, medical insurance status, history of drinking and education level significantly affected PCU in 2009-2011. Having medical insurance was no longer a positive influencing factor of PCU, while high income had a negative effect on PCU, in 2011-2015.

Conclusions PCU from 2004 to 2015 was low and the health reform in China may lack sustainable effect on PCU. Further studies on how to ensure sustainability of PCU are necessary, and further reforms on preventive care services should be aimed at different ages, rural areas and participants without history of disease.

\section{INTRODUCTION}

Following rapid economic growth and social development, China has become the second largest economy worldwide. ${ }^{1}$ While the disparity in healthcare utilisation has
Strengths and limitations of this study

- This is the first study aimed to assess changes in preventive care utilisation and its relationship with the healthcare reform.

- Multilevel mixed-effects logistic regression models were used.

- A cross-sectional study using data of adults from five waves (2004-2015) of the China Health and Nutrition Survey was conducted.

- The use of self-reported data can potentially introduce recall bias, or dishonest responses or acquiescence bias.

widened, China's healthcare system faces new challenges, such as increased healthcare demands and expenditure, inefficient use of healthcare resources, and unsatisfying implementation of disease management guidelines. ${ }^{2}$ Facing these challenges, China has unveiled a huge and complex health reform plan in $2009^{3}$ to be implemented in three sequential phases according to the macro guidelines: first phase in 2009-2011, second phase in 2012-2015 and third phase in 2016-2020. A series of policies have been developed and implemented to improve various systems in China. The overall goal of the reform is to establish and improve the basic healthcare system for both urban and rural residents and to provide residents with secure, efficient, convenient and affordable healthcare services. This is a comprehensive reform anchored in four interdependent areas: healthcare insurance, public health service, medical security or public health insurance, and secure pharmaceutical supplies. The services related to preventive 
health services are mainly concentrated on public health services and insurance. Although the general public thought that the 2009 health reform has generally shown progress, ${ }^{45}$ researchers have argued that the recent health reform in China is biased towards disease treatments and overlooked preventive care. ${ }^{6}$ Public investment has been gradually limited to the treatment domain. In Gansu and Tianjin expenditure on preventive care accounts for only $1 \%$ or $2 \%$ of the total health expenditure. $^{7}$

With population ageing and the prevalence of chronic diseases increasing, strong evidence has been documented that effective preventive health services and interventions for early detection remain as effective strategies in reducing mortality and disability, ${ }^{7-9}$ as well as chronic disease burden. Preventive care helps find and stop health issues before people can acquire symptoms. Preventive care service encompasses a wide range of healthcare measures that can be undertaken to identify and prevent the occurrence of disease early, and is particularly more cost-effective than medical treatment. ${ }^{10}$ Preventive care services include general physical examination and selective programmes designed for detecting particular diseases in certain target populations, such as prenatal examination, postnatal examination, gynaecological examination, blood pressure screening, cancer screening, and vision or hearing examination. In China, selective programmes are often prepackaged (eg, maternal care, childcare and geriatric care) and promoted by public health agencies. ${ }^{11}$ Some selective programmes may be fully funded by government budgets, while others may be treated as an integral part of disease management regimens and covered by medical insurance schemes. General physical examination is usually consumer-driven and is not specific to a particular disease, and varies significantly in scope and content, and usually paid out of pocket or by the employer.

Underutilisation of preventive care services may result in failure to identify treatable healthcare problems and prevent potentially life-threatening diseases. In the past 10 years, research results have shown that preventive care utilisation (PCU) among Chinese adults does not exceed $7 \%,{ }^{12-14}$ which is far from the results of foreign research. ${ }^{15-18}$ Previous research has indicated that education level, income, ethnic group and age are associated with PCU among adults. ${ }^{18-21}$ Literature in China showed that age, gender and health problems play important roles in service utilisation. Urban-rural disparity and medical insurance were also indicated to influence PCU. ${ }^{14} 22{ }^{23}$ However, few studies emphasised PCU and its relationship with healthcare reform. Our understanding about how people seek further PCU is limited before and after the healthcare reform in China, despite the general consensus on the need to shift focus from disease treatment to wellness and prevention. This study aimed to assess changes in PCU and its relationship with the healthcare reform.

\section{METHODS}

\section{Data source and participants}

This study uses data from five waves of the China Health and Nutrition Survey (CHNS), an ongoing national household-based study. The CHNS has adopted a multistage random cluster sampling method in nine Chinese provinces (Guangxi, Guizhou, Heilongjiang, Henan, Hubei, Hunan, Jiangsu, Liaoning and Shandong), with different geographies, level of economic development and health indicators established by the University of North Carolina Chapel Hill and the Chinese Center for Disease Control and Prevention. ${ }^{24}$ The CHNS started in 1989, with subsequent examinations every 2-4 years, for a total of 10 waves between 1989 and 2015. CHNS participants exhibit a wide range of socioeconomic factors (income, employment, education and modernisation) and other related health, nutritional and demographic factors. Written informed consent is obtained from individual participants. ${ }^{24}$ This study focuses on the changes in adults undergoing PCU and the influencing factors before and after the 2009 healthcare reform. Two-wave data before and after 2009 were selected (2004-2015) for analysis. The years from 2004 to 2009 were defined as before the medical reform and from 2011 to 2015 as after the medical reform. In addition, the years from 2009 to 2015 were divided into the first phase (2009-2011) and the second phase (2011-2015) on the basis of the 2009 health reform plan. ${ }^{3}$ Individuals younger than 18 years old who were not from the previous nine provinces were excluded. We also excluded samples with missing key variables. The sample sizes for analysis were 9960 in 2004, 9888 in 2006, 10286 in 2009, 9709 in 2011, and 10628 in 2015 .

\section{Patient and public involvement}

No patients were involved.

\section{Outcome variables description}

PCU was assessed by questions during a nurse interview, and PCU in the last 4 weeks and its location were analysed. The following questions were used in the survey: 'During the past fourweeks, did you receive any preventive care service?', 'What type of preventive care services did you receive?' and 'Where did you receive the prevention care service? (1) primary health care institution; (2) secondary hospital; (3) tertiary hospital; (4) other medical institution'. A positive answer to the first question was defined as PCU user. Preventive care services include general physical examinations, disease screening (eg, blood pressure screening, blood test and cancer screening) and other examinations designed for certain target populations (eg, prenatal examination, postnatal examination, gynaecological examination, and vision or hearing examination).

\section{Independent variables description}

The following were the variables used in this study:

- Demographic characteristics (ie, gender, age, marital status and education). Age was categorised into three 
age groups (18-44, 45-59, and 60 and above). Marital status was categorised as married and non-married status (including divorced, widowed, separated and never married). Educational attainment was classified into three levels, namely low (literate/primary school), medium (junior middle school) and high (high middle school or higher). Nationality was set as 'Han' and minority.

- Socioeconomic status (ie, per capita annual family income and medical insurance status). The per capita annual family income was recoded into tertiaries as low, medium and high. Medical insurance status was defined by asking 'Do you have any medical insurance? Yes/No'.

- Environmental factors (ie, urbanisation level of residence area and region). Urbanisation level of residence area was recoded into tertiaries as low, medium and high, and region was categorised as urban and rural.

- Lifestyle and health status (ie, history of smoking and drinking and history of disease). The health status variable includes history of disease, which is dichotomised and defined by doctors. All participants were asked whether they experienced any one of the common diseases: high blood pressure, diabetes, myocardial infarction, transient ischaemic attack, stroke, cancer, asthma or chronic obstructive pulmonary disease.

\section{Statistical analysis}

All data management and statistical analyses were performed with Stata V.15.0. Analysis was conducted by comparing preventive healthcare utilisation and other explanatory variables from different survey year samples, using pooled cross-sectional CHNS data for 2004-2015. The $\chi^{2}$ test was used to compare the differences between groups for categorical variables and analysis of variance for continuous variables. The overall age-standardised prevalence of PCU and specific use of examinations were measured by estimate means. We chose variables (ie, gender, age, education level, income level, having medical insurance, environmental factors, lifestyle and health status variables) that were often discussed after the health reform in the multilevel mixed-effects logistic regression analysis to explore the factors that affected the use of preventive healthcare among adults. We chose participants as the random intercept in the mixed-effect logistic regressions, and the regression models fully adjusted for the same set of control variables. According to the criteria for assessing model fit, the log-likelihood statistics of the fitted model indicate that the model fits well. A p value of 0.05 was considered significant.

\section{RESULTS}

Table 1 shows the demographic and socioeconomic characteristics of all the participants across five waves of the survey. In 2004-2015, the number of participants aged 60 years or over has increased from $22.1 \%$ to $33.4 \%$. In the five surveys, approximately $48 \%$ were female participants. The number of participants with a history of disease has increased from $14.1 \%$ to $20.7 \%$, and most respondents were married. Level of education, urbanisation and per capita annual income of families have likewise increased. Nearly $58 \%$ of participants worked and nearly $65 \%$ lived in rural areas. Medical insurance coverage rate grew from $26.8 \%$ in 2004 to almost $97.1 \%$ in 2015 . The number of people who ever drank or smoked has decreased across the five-wave surveys.

PCU in 2004-2015 among adults was 3.29\%, 3.13\%, $3.77 \%, 4.95 \%$ and $2.73 \%$, respectively. PCU in 2006-2009 showed a certain increase, and the increase during the first stage of the health reform (2009-2011) was more obvious. However, PCU decreased during the second phase of the health reform (2011-2015), as shown in figure $1 \mathrm{~A}$, and utilisation of a specific type of preventive care was different. Utilisation of general physical examination in 2004-2015 among adults was 1.33\%, 1.48\%, $1.66 \%, 2.85 \%$ and $1.1 \%$, respectively (figure 1B), and was higher than the rate of disease screening and other examinations in 2004-2015. The rate of disease screening has not changed much before and after the health reform, which was close to $1 \%$.

Figure 2 shows the changes in PCU by different subgroups over the 11 years. Figure 2A shows that PCU among older participants was higher than the other two younger age groups, and was also higher in women than in men (figure 2B). Gender disparities were also found with regard to choices of location for PCU (figure 3A). More participants accessed preventive care at primary health institutions after the health reform. After the health reform, the choice gap between men and women narrowed. Residents from urban and rural areas also have different choices of location with regard to PCU. Participants who came from rural areas were more likely to choose primary health institutions compared with urban participants. During the first phase of the health reform, urban-rural disparities with regard to choice of location became even larger than it was before 2009, and during the second phase it was almost the same as it was before 2009 (figure 3B).

The OR among various factors for PCU during the different years of the survey among adults is shown in figure 4A-C. Whether before or after the health reform, history of disease was a positive influencing factor of PCU. Having a medical insurance was also a positive influencing factor of PCU in all surveys except in 2015 $(\mathrm{OR}=0.73, \mathrm{p}<0.05)$. Female gender was positively associated with PCU in 2004, 2006, 2011 and $2015(\mathrm{p}<0.05)$, but not in 2009. Conversely, residing in rural region was a negative influencing factor of PCU in 2004, 2006, 2019 and 2015, but not in 2011 ( $\mathrm{OR}=0.96, \mathrm{p}>0.05)$. Participants with high income were more likely to use preventive care services in 2004, 2009 and 2011, and were less likely to use preventive care services in 2015. Older participants (age $\geq 60$ ) were 1.52 times more likely than their younger (age 18-44) counterparts to choose preventive care 
Table 1 Demographic and socioeconomic characteristics of participants across the five waves of the survey (CHNS 20042015)

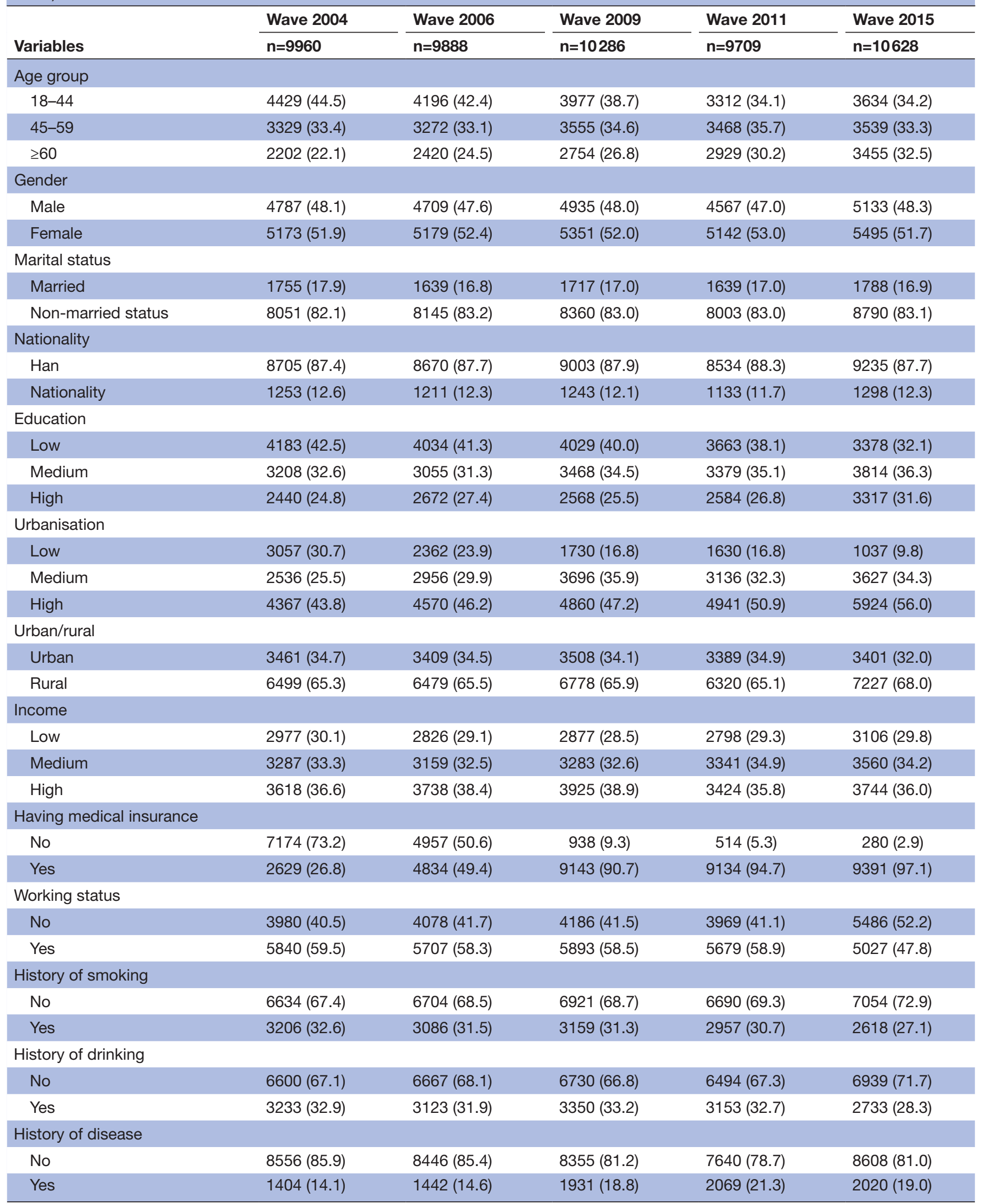

Data are presented as $\mathrm{n}(\%)$ for categorical measure.

CHNS, China Health and Nutrition Survey. 

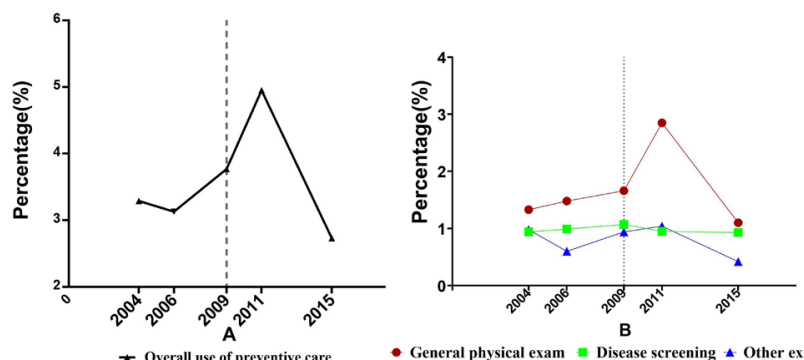

Figure 1 (A) Utilisation of overall preventive care and (B) specific types of preventive care utilisation in China Health and Nutrition Survey in 2004-2015.

$(\mathrm{OR}=1.52, \mathrm{p}<0.05)$ in 2011 (figure 4D). Also, participants with medium and high education level were 1.40 and 1.57 times more likely than their counterparts with low education level to choose preventive care $(\mathrm{OR}=1.40, \mathrm{p}<0.05$; $\mathrm{OR}=1.57, \mathrm{p}<0.05$ ) when the confounding variables were held constant. Participants with a history of drinking were more likely to use preventive health services than those with no drinking history $(\mathrm{OR}=1.29, \mathrm{p}<0.05)$ at the first phase of the health reform. At the second phase of the health reform (figure $4 \mathrm{E})$, smokers $(\mathrm{OR}=1.49$, $\mathrm{p}<0.05)$ were more likely to use preventive care than non-smokers.

\section{DISCUSSION}

This study finds that the number of people at high level of urbanisation and the ageing population continued to increase across the years of the five surveys. This case may be related to recent ageing and gradual increase in urbanisation in China. By the end of 2017, urbanisation rate has reached $49.7 \%$, and the proportion of the elderly population over 65 has reached $8.9 \% .^{25}$ In addition, the proportion of participants with medical insurance has also increased from $50 \%$ (2006) to $97 \%$ (2011). China's New Cooperative Medical Scheme was established in 2003 in response to the deterioration in access to health services in rural areas. Furthermore, the focus of the first phase (2009-2011) of the health reform was to provide economic coverage and expand social medical insurance coverage. From this perspective, the effects of the first stage of the health reform and the new rural cooperative medical system were remarkable. ${ }^{46}$ This scenario may also explain why no significant difference was observed in the PCU of the population with medical insurance at the
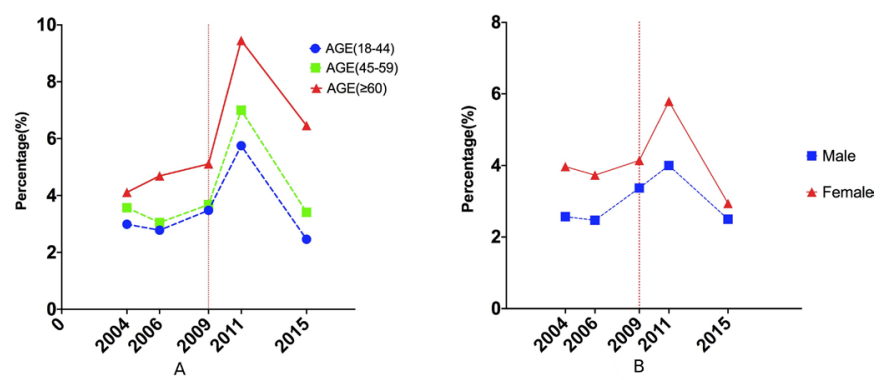

Figure 2 Utilisation of preventive care by $(A)$ age and $(B)$ gender in China Health and Nutrition Survey in 2004-2015.
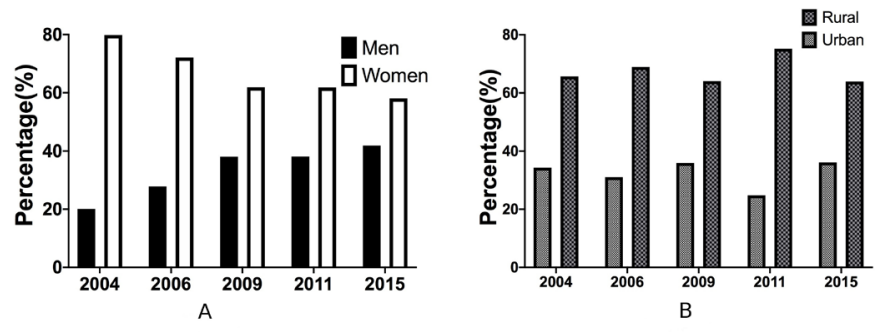

Figure 3 Choice of primary health institution by (A) gender and (B) region in China Health and Nutrition Survey in 20042015.

second phase of the health reform, with over $95 \%$ of the population (1.3 billion) having been covered by the Basic Social Medical Insurance in China in 2012. ${ }^{27}$

This study shows that PCU among participants was low in 2004-2015. Although PCU has increased from 2009 to 2011, the gap between China and other countries remains wide. ${ }^{17-19} 2829$ The lag effect of the policy may be one of the reasons for the highest value in 2011. The different focus of the health reform during the first phase (2009-2011) and the second phase (2011-2015) may be one reason for the turnaround. The first phase emphasised expanding social health insurance coverage for all, strengthening infrastructure, and restoring basic medical and health service, so it may have paid more attention to the rate of residents' health behaviours and only showed short-term effects. Also, we found that more participants used preventive care at primary health institutions after the health reform. These findings may prove that the

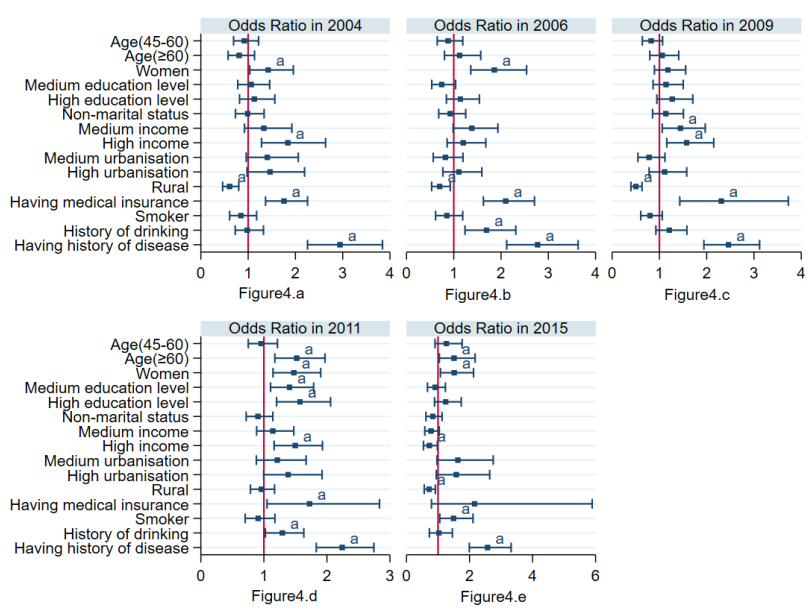

Figure 4 Multilevel mixed-effects logistic regression analysis of PCU in CHNS 2004-2015. $\mathrm{P}<0.05$. Male gender, low education level, low urbanisation, married, low per capita income, no medical insurance, no smoking, no drinking and no disease history were treated as reference categories, respectively. Non-marital status (including divorced, widowed, separated and never married). OR among various factors of PCU in (A) 2004, (B) 2006, (C) 2009, (D) 2011 and (E) 2015. CHNS, China Health and Nutrition Survey; PCU, preventive care utilisation. 
implementation of the first phase of the policy was effective. However, the second phase prioritised the transformation of resources into effective services, and PCU has dropped off a cliff at the second phase of the reform, which may indicate that health reform in China may lack sustainable PCU. Further studies on how to ensure sustainability are necessary.

Our study showed that women had higher PCU than men whether before or after the health reform, similar to previous studies. ${ }^{22}{ }^{30}$ It is possible that women are more concerned with health-related messages. ${ }^{31}$ Gender stereotyping, where men are believed to be stronger, tougher and more robust than women, as well as men's beliefs and own perceptions of themselves as being invulnerable, may lead to men using preventive care service less. ${ }^{32}$ With regard to age, PCU among older participants was higher than other younger-aged participants between 2004 and 2015, which is consistent with the fact that older people were at a greater risk of disease and death than young people. We were not surprised to find the results of multilevel mixed-effects logistic regression analysis statistically significant only in 2011 and 2015 by controlling the confounding variables. As one goal of the healthcare reform in 2009 in China, 'equalization of basic public health services' was set by the Chinese government and the 'National Basic Public Health Service Program' was also launched. ${ }^{33}$ In 2015, the State Council has issued guidelines for building a tiered healthcare delivery system to overhaul the existing hospital-centric approach and emphasised the importance of improving the capacity of primary medical and health services. ${ }^{34}$ Basic public health services are defined by the Chinese government under 10 categories and are delivered free of charge through public health agencies (including local Centers for Disease Control and Prevention and primary care facilities). Most of these services are selective, targeting a specific group of population, such as women (eg, postnatal home visits and breast cancer screenings), children (eg, physical development monitoring and vaccinations), elderly (eg, physical examinations) and people with chronic conditions (eg, management of hypertension, type II diabetes and severe mental illness). ${ }^{35}$ This may be one reason why women were more likely to use preventive care services. Besides, other participants who were not covered by the basic public health service packages would have to pay for such services, which may lead to lower PCU.

Whether before or after the health reform, history of disease is a driving factor of PCU, which is most consistent with the results of previous studies. ${ }^{19212236}$ This may also be related to the services provided by the basic public health services mentioned earlier and to the people with illness using preventive care during doctor visitations. ${ }^{22}$ This finding also suggests that participants who did not have history of disease often neglect PCU. A concerning issue was that more than $50 \%$ of patients with hypertension have never received blood examinations. ${ }^{37}$ Emphasis on treatment than prevention in China is another concern. Many people do not consider prevention care seriously until they acquire symptoms or were diagnosed with a certain disease. In fact, all residents need preventive care services regardless of their health status. Health promotion programmes and preventive care services should be strengthened, and more attention should be paid on how to promote use of PCU among participants who never have history of disease.

Although closing the urban-rural gap in health services has been one of the core policy goals of the recent health reform, ${ }^{38}$ urban-rural disparities in PCU were found before and after the health reform, except in 2011. Urban-rural disparities with regard to choice of location for preventive care services were also found. The absence of urban-rural disparity in preventive care in 2011 may be a reflection of the effect of the $¥ 850$ billion that had been spent in expanding health insurance coverage, improving primary care, establishing essential medicines system and promoting public health services between 2009 and $2011,{ }^{39}$ and it may be a reflection of the overall low level of preventive care usage in both rural and urban China. In fact, people in rural areas usually experience shortage of healthcare providers, have low socioeconomic status and lack social support. ${ }^{4041}$ Different welfare systems also existed between urban and rural areas, including social benefits systems including health insurance. ${ }^{42}$ Urban-rural disparities in socioeconomic development and burden of disease still existed, reflecting a positive discrimination (favourable policies towards the poor) where providing preventive care to rural populations is preferable.

Previous studies observed that household income and education level were two primary factors that caused disparities in PCU after the 2009 health reform. ${ }^{13}{ }^{14}$ We found participants with high income were more likely to use preventive care services before and after the health reform, except in 2015. Empirical evidence shows that many poor people would disregard the much-needed medical care as well as preventive care services if they have to sacrifice their basic living budget (such as food and housing consumes) for these services. ${ }^{5}$ Healthcare is largely exposed to market forces, and financial burden may still be a barrier to PCU among the poor in China. Participants with high income were less likely to use preventive care services in 2015. This may be due to the fact that, among the participants in 2015, the proportion of people with high income was lower than in 2009, but may also be that the population of people with high income was mainly concentrated in the 45-59 age range in 2015. The year 2015 was the second stage of the health reform, the goal of which was to continue to improve public health services and expand employee insurance, and requires annual medical examinations for working employees. However, the 45-59 population in China is in the retirement stage and thus may not receive medical examinations paid by employee insurance. These measures may lead to the possibility of preventing those lower than the low-income population from using healthcare services. It also suggests that further stratification studies may be required. 
However, the association between education level and PCU before and after the 2009 health reform was only found in 2011 in our study, which is not exactly the same as Lee $e t a l$ s finding. ${ }^{13}$ This may be due to the fact that we used age-standardised prevalence of PCU in this study. All citizens should have equal access to basic preventive care, regardless of their education level and socioeconomic status. Based on our findings, the Chinese central government should implement health education campaigns for people of all education levels, not only those with lower education. Further reforms should be launched with a focus on preventive care services for all Chinese residents.

The results of the present study should be interpreted with caution due to several limitations. First, secondary data were used to investigate this topic of interest. Although the study used a 'before-after' design, it is only a descriptive study. There is ambiguity as to whether the changes are mainly from the reform or due to other unobserved changes, or that the difference might come from the sample. It is necessary to conduct more follow-up studies. Self-reported bias could be a challenge to this study, although it is a common limitation for most survey-based research with secondary data analysis. Second, only data gathered 6 years before and after the implementation of the healthcare reform are used, and the recall period was relatively short, which may not actually capture the actual use of preventive services. The response to the healthcare reform effect may be temporary. Third, preventive care usage was captured by only a few simple questions and the survey was only conducted in nine specific cities. The findings also only account for the participants included in this study. The holistic situation in China is to be demonstrated and further studied. Long-term PCU also remains unknown due to PCU being evaluated only by asking for those that took place in the past 4 weeks when the study participants completed the survey. This could also be one major reason that explains why PCU was so low in the CHNS data set. More research is needed to explore long-term PCU.

\section{CONCLUSION}

In 2004-2015, PCU among adults remained at low level. The health reform in China may lack sustainable PCU. Further studies on how to ensure sustainability are necessary. Considering 2009 as a turning point, only region and history of disease influenced PCU before and after the health reform. Other factors changed to varying degrees. The positive news for China is that many PCUs can be improved by using interventions that are practical and affordable. Our findings suggest that governments, especially in developing countries such as China, should warrant broad-based global strategy to young age groups, rural regions and participants without history of disease, and expend greater efforts in PCU through more effective ways.
Author affiliations

${ }^{1}$ School of Public Health and Management, Chongqing Medical University, Chongqing, China

${ }^{2}$ Research Centerfor Medicine and Social Development, Chongqing Medical University, Chongqing, China

${ }^{3}$ Collaborative Innovation Centerof Social Risks Governance in Health, Chongqing Medical University, Chongqing, China

${ }^{4}$ The Hospital on Integration of Chinese and Western Medical Science in Shapingba District, Chongqing, China

${ }^{5}$ Department of Behavioral and Environmental Health, Jackson State University, Jackson, Mississippi, USA

${ }^{6}$ Human Nutrition Department, QU Health, Qatar University, Doha, Ad Dawhah, Qatar

Acknowledgements This research uses data from the China Health and Nutrition Survey (CHNS). All authors thank the National Institute for Nutrition and Health, Chinese Center for Disease Control and Prevention, Carolina Population Center, University of North Carolina at Chapel Hill, and NIH Fogarty International Center for financial support provided to the CHNS data collection.

Contributors TTW conducted the statistical analyses of the data and prepared the manuscript. MZ visualised the manuscript. YZ, XL and WWL helped revise the manuscript. QY, MS and ZMS helped review and provide critical comments to the manuscript. All authors were involved in data interpretation and made substantial contributions to critically revising the manuscript before submission. All authors checked and proof-read the final version of the manuscript.

Funding This research was funded by the Chongqing Federation of Social Science Circles (no. 2017ZDYY24) and was supported by the Top Notch Talent Students' programme of Chongqing Medical University (BJRC201804).

Competing interests None declared.

Patient and public involvement Patients and/or the public were not involved in the design, or conduct, or reporting, or dissemination plans of this research.

Patient consent for publication Not required.

Ethics approval Approval for the primary study was granted by the Institutional Review Committees of the University of North Carolina (USA) and the National Institute of Nutrition and Food Safety (China).

Provenance and peer review Not commissioned; externally peer reviewed.

Data availability statement Data are available in a public, open access repository. Data are available upon reasonable request. The data sets used for this study are available on request from the China Health and Nutrition Survey at https://www. cpc.unc.edu/projects/china.

Open access This is an open access article distributed in accordance with the Creative Commons Attribution Non Commercial (CC BY-NC 4.0) license, which permits others to distribute, remix, adapt, build upon this work non-commercially, and license their derivative works on different terms, provided the original work is properly cited, appropriate credit is given, any changes made indicated, and the use is non-commercial. See: http://creativecommons.org/licenses/by-nc/4.0/.

ORCID iDs

Ting Ting Wu http://orcid.org/0000-0001-7951-9312

Yong Zhao http://orcid.org/0000-0001-9290-109X

\section{REFERENCES}

1 Blumenthal D, Hsiao W. Lessons from the East--China's rapidly evolving health care system. N Engl J Med 2015;372:1281-5.

2 Chen Z. Launch of the health-care reform plan in China. Lancet 2009;373:1322-4.

3 Yip WC-M, Hsiao WC, Chen W, et al. Early appraisal of China's huge and complex health-care reforms. Lancet 2012;379:833-42.

4 Yip W, Fu H, Chen AT, et al. 10 years of health-care reform in China: progress and gaps in universal health coverage. Lancet 2019;394:1192-204.

5 Zhang L, Liu N. Health reform and out-of-pocket payments: lessons from China. Health Policy Plan 2014;29:217-26.

6 Yang L, Zhang X, Tan T, et al. Viewpoint: prevention is missing: is China's health reform reform for health? J Public Health Policy 2015;36:73-80.

7 Marin MG, Zitter JN. Expenditures associated with preventive healthcare. Prev Med 2004;39:856-62. 
8 Spalding MC, Sebesta SC. Geriatric screening and preventive care. Am Fam Physician 2008;78:206-15.

9 Nelson DE, Bland S, Powell-Griner E, et al. State trends in health risk factors and receipt of clinical preventive services among US adults during the 1990s. JAMA 2002;287:2659-67.

10 Maciosek MV, Coffield AB, Edwards NM, et al. Priorities among effective clinical preventive services: results of a systematic review and analysis. Am J Prev Med 2006;31:52-61.

11 Wang L, Wang Z, Ma Q, et al. The development and reform of public health in China from 1949 to 2019. Global Health 2019;15:45.

12 Dai B. Does China's new cooperative medical scheme promote rural elders' access to healthcare services in relation to chronic conditions? Int Health 2015;7:32-41.

13 Lee Y-H, Chiang T, Liu C-T. Residents' educational attainment and preventive care utilization in China. Int J Health Care Qual Assur 2018;31:41-51.

14 Liu X, Li N, Liu C, et al. Urban-Rural disparity in utilization of preventive care services in China. Medicine 2016;95:e4783.

15 Abrahamyan A, Bussel II BJR, et al. Utilization of primary care and preventive health services amongst individuals in same-sex and opposite-sex partnerships; a cross-sectional observational analysis of medical expenditures panel survey (Meps), 2003-2001. J Gen Intern Med 2017;32:S89.

16 Y-j L, Chen B, Liu T-C, et al. The impact of family structure on utilization of preventive care services among children under national health insurance in Taiwan. J Fam Econ Issues 2012;33:453-63.

17 Rommel A, Hoebel J, Starker A. 1.4-O1Utilization of preventive care among people with migrant background. results from the German health interview and examination survey for adults (degS). Eur $J$ Public Health 2018;28:26-7.

18 Vaidya V, Partha G, Howe J. Utilization of preventive care services and their effect on cardiovascular outcomes in the United States. Risk Manag Healthc Policy 2011;4:1-7.

19 Cheah YK, Tang CF. Factors influencing the use of preventive medical care in Malaysia: evidence from national health and morbidity survey data. Asian Econ J 2017;31:119-37.

20 Lin J-D, Wu J-L, Lee P-N. Healthcare needs of people with intellectual disability in institutions in Taiwan: outpatient care utilization and implications. J Intellect Disabil Res 2003;47:169-80.

21 Yen S-M, Kung P-T, Tsai W-C. Factors associated with free adult preventive health care utilization among physically disabled people in Taiwan: nationwide population-based study. BMC Health Serv Res 2014; $14: 610$.

22 Huang C, Liu C-J, Pan X-F, et al. Correlates of unequal access to preventive care in China: a multilevel analysis of national data from the 2011 China health and nutrition survey. BMC Health Serv Res 2016;16:177.

23 Lee Y-H, Chang Y-C, Liu C-T. Preventative care utilization and associated health-related measurements among older adults following the 2009 health reform in China. Int J Health Plann Manage 2019;34:e1135-48.

24 Popkin BM, Du S, Zhai F, et al. Cohort profile: the China health and nutrition survey--monitoring and understanding socioeconomic and health change in China, 1989-2011. Int J Epidemiol 2010;39:1435-40.
25 China Nboso. China's census. Available: http://datastatsgovcn/ easyqueryhtm?cn=C01\&zb=A0G0Z\&s]=2018 [Accessed 30 Dec 2019].

26 Yang W. China's new cooperative medical scheme and equity in access to health care- evidence from a longitudinal household survey. Int J Equity Health 2013;12:13.

27 China NBoSoPsRo. 2012 National Economic and Social Development Statistical Bulletin:The coverage of basic medical insurance in China has been expanded, 2012. Available: http://wwwstatsgovcn/tjsj/tjgb/ndtjgb/qgndtjgb/201302/ t20130221_30027html

28 Yom Din G, Zugman Z, Khashper A. The impact of preventive health behaviour and social factors on visits to the doctor. Isr J Health Policy Res 2014;3:41.

29 Musich S, Ignaczak A, McDonald T, et al. Self-Reported utilization of preventive health services by retired employees age 65 and older. $J$ Am Geriatr Soc 2010;49:1665-72.

30 Owens GM. Gender differences in health care expenditures, resource utilization, and quality of care. J Manag Care Pharm 2008;14:2-6.

31 Horch K, Wirz J. [People's interest in health information]. Bundesgesundheitsblatt Gesundheitsforschung Gesundheitsschutz 2005;48:1250-5.

32 Sloan C, Conner M, Gough B. How does masculinity impact on health? A quantitative study of masculinity and health behavior in a sample of UK men and women. Psychol Men Masc 2015;16:206-17.

33 Council TS. Opinions of the state council of the CPC central committee on deepening the reform of medical and health system. Available: http://wwwgovcn/zwgk/2009-07/14/content_1365335htm [Accessed 30 Dec 2019].

34 Council GOotS. Guidance of the general office of the state Council on promoting tiered delivery system. Available: http://wwwgovcn/ zhengce/content/2015-09/11/content_10158htm [Accessed 30 Dec 2019].

35 Qin HJ CB. Technical specification for basic public health service. Beijing: People's Medical Publishing House, 2013.

36 Quinn BC, Catalano RA, Felber E. The effect of community-level unemployment on preventive oral health care utilization. Health Serv Res 2009;44:162-81.

37 Qingyue M, Shenglan T. Universal health care coverage in China: challenges and opportunities. Procedia Soc Behav Sci 2013:77:330-40.

38 Daemmrich A. The political economy of healthcare reform in China: negotiating public and private. Springerplus 2013;2:448.

39 Yang Q, Dong $\mathrm{H}$. Have health human resources become more equal between rural and urban areas after the new reform? Int $J$ Health Policy Manag 2014;3:359-60.

40 Haggerty JL, Roberge D, Lévesque J-F, et al. An exploration of ruralurban differences in healthcare-seeking trajectories: implications for measures of accessibility. Health Place 2014;28:92-8.

41 Chen Y, Yin Z, Xie Q. Suggestions to ameliorate the inequity in urban/ rural allocation of healthcare resources in China. Int $J$ Equity Health 2014;13:34

42 Afridi F, Li SX, Ren Y. Social identity and inequality: the impact of China's hukou system. J Public Econ 2015;123:17-29. 